\title{
THE
}

\section{Consumer Wellbeing in Asia: Introduction to the Special Issue}

Jing Jian Xiao

University of Rhode Island, jjxiao@uri.edu

Eunju Ko

May O. Lwin

Follow this and additional works at: https://digitalcommons.uri.edu/hdf_facpubs

The University of Rhode Island Faculty have made this article openly available.

Please let us know how Open Access to this research benefits you.

This is a pre-publication author manuscript of the final, published article.

Terms of Use

This article is made available under the terms and conditions applicable towards Open Access Policy Articles, as set forth in our Terms of Use.

\section{Citation/Publisher Attribution}

Xiao, J.J., Ko, E. and Lwin, M.O. (2021), Consumer Wellbeing in Asia: Introduction to the Special Issue. J Consum Aff. Accepted Author Manuscript. https://doi.org/10.1111/joca.12420 Available at:

https://doi.org/10.1111/joca.12420

This Article is brought to you for free and open access by the Human Development and Family Science at DigitalCommons@URI. It has been accepted for inclusion in Human Development and Family Science Faculty Publications by an authorized administrator of DigitalCommons@URI. For more information, please contact digitalcommons-group@uri.edu. 
Journal of Consumer Affairs

Consumer Wellbeing in Asia: Introduction to the Special Issue

$$
\text { Jing Jian Xiao' }{ }^{1} \text { Eunju Ko², May O. Lwin }{ }^{3}
$$

Consumer wellbeing refers to safety, fairness, satisfaction, sustainability, emotional positivity, security, freedom, and healthfulness which may be sought through consumer products and services obtained from marketplaces. Consumer wellbeing can be measured in various dimensions such as economic, financial, physical, psychological, social, and culture. This special issue focuses on consumer issues in fast changing Asia as many important consumer issues in Asia are under-studied in comparison to the literature about the West. With Asia having a large, $60 \%$ of the world population and Asian countries are highly diverse in terms of economic developments, social systems, and cultural traditions, many important issues related to consumer spending, health, and finance need be investigated and studied. Such research will enrich the global literature of consumer affairs and inform public policies to advance consumer interests.

For this special issue, 47 submissions were received and 20 were accepted. Articles are broadly divided to three sets: health, sustainability, and finance. Following are brief introductions of these articles.

Health. On the health front, the papers in this issue spanned an array of health concerns, including topics which are indigenous to Asia. Gao, Mei, Yang, Zhao and Li examined the issue of food waste using empirical data from China and found the important role of psychological cultural factors - namely the influence of "mianzi" or vanity in excessive food consumption and wastage of food. Leong, Soo, Minton and Tambyah utilized survey data from Singapore to examine economic hardships in the context of neighbourhoods in this densely populated country and found important patterns regarding wellbeing links especially with vulnerable consumers. The relation between economic hardship and consumer wellbeing was found to be moderated by neighborhood-level socioeconomic status and diversity. Another paper by Nguyen, Nguyen, and Pham interviewed stakeholders to examine rhino horn demand and consumption in traditional health mileau of Vietnam. The authors found that wildlife endangerment is a multifaceted issue driven by a web of non-scientific health related claims and beliefs. The authors show that the processes through which Vietnamese consumers form their beliefs and attitudes, normalize and justify consumption of the rhino horn. Finally, Kwak, Kim, Kim and Choi examined digital usage and digital shopping via online and mobile devices and investigate their relationships with wellbeing using a public data from South Korea. Online usage and online shopping were related to wellbeing, and complex relationships including digital natives and privacy concerns as moderators surfaced.

Sustainability. Six papers examined factors associated with sustainability and wellbeing topics such as environmental consciousness, happiness, wellbeing in consumption behavior in China and Korea. Hao

\footnotetext{
${ }^{1}$ Professor, Department of Human Development and Family Science, College of Health Sciences, University of Rhode Island, Kingston, RI 02881, USA. Email: xiao@uri.edu

2 Professor, Department of Clothing and Textiles, College of Human Ecology, Yonsei University, Seoul, Republic of Korea 03722. Email: ejko@yonsei.ac.kr

3 President's Chair Professor, Wee Kim Wee School of Communication \& Information, Nanyang Technological University, 31 Nanyang Link, Singapore 637332. Email: tmaylwin@ntu.edu.sg
} 
and Chenyue showed that environmental consciousness and health consciousness influence consumers' ecological purchase intentions regarding eco-friendly products and self-protective products. Haze is a strong moderator for arousing both types of consciousness; and perceived-self competence moderates the relationships of such key concepts. Duh, $\mathbf{Y u}$, and $\mathbf{N i}$ examined the relationship between the Chinese Millennials' happiness and materialism. Conceptual model was developed using two life-course theories, self-esteem, and money attitudes. Specifically, self-esteem predicts money attitude dimensions, which can help and hinder materialism. Zhang, Pan, Liu, Zhang, and Chen explored the influence of social ties between spenders and recipients on recipients' happiness with mediation effects of psychological needs satisfaction. Results showed that gifts from strong social ties lead to recipients' greater happiness than those from weak social ties. The happiness effect of social ties is explained through relatedness satisfaction and competence satisfaction, but not autonomy satisfaction.

Hwang and Nam investigated the moderating effect of disability on the relationship between middleaged consumers' wellbeing and their social media use, through mediating effect of social capital using secondary data from South Korea. Results showed consumers with disabilities were less active on social media, suggesting they are likely to experience restrictions on social media use. Disability had moderating effects between social media use and wellbeing bonded by social capital. An, Jeong and Youn examined effects of art appreciation on wellbeing through five studies based on administrative dataset and lab experiments. This study showed that consumers' experience of art, including artistic commercial products enhances consumers' wellbeing by inducing a sense of inspiration. Various forms of art (e.g., paintings, song lyrics) and various commercial products depicting artistic images (e.g., computer screen saver, handbag) were significantly effective. Finally, Ryu and Kim examined how time availability, relative monetary contribution and gender ideology are associated with South Korean couple's contribution to domestic work among married couples. Using longitudinal data in South Korea, results showed that hours worked and relative wage were associated with the time that couples spend on domestic work.

Finance. Four papers examined factors associated with saving and investing behavior. With three experiments conducted in China, Yang, Zheng, and Chen examined the effect of social exclusion on fixed savings (long term savings). They found that men and women display different fixed savings behavior in response to social exclusion. In particular, social exclusion decreases men's fixed savings intention, while social exclusion does not affect women's fixed savings intention. Baker, Tomar, Kumar, and Verma examined the financial literacy level of professional women and its relation to their retirement planning behavior in India. They found that the respondents display low levels of financial literacy. Further, a woman's age, income, finance profession, and understanding of advanced financial concepts are key factors associated with retirement planning behavior. Chiang estimated Chinese individuals' financial capability and examined the association between financial capability and household investment management. With data from the China Family Panel Studies, he found that less than $12 \%$ of individuals have financial capability far below the average. In addition, his results showed that individuals with higher financial capability are more likely to take control of household investment alone than to share investment decisions with spouses. Lu, Xiao, and $\mathbf{W u}$, with data the China Household Finance Survey, examined the role of financial literacy in improving household asset allocation. They demonstrated that the higher the household's financial literacy, the higher the household's score in the asset allocation evaluation. Their further analysis showed that the optimization effect of financial literacy on household asset allocation is greater among households that are wealthy, have higher education, and are located in areas with better regional financial development. 
Four papers explored potential influencing factors on financial or general wellbeing. Chen, Jiang, and Gu investigated the association between household savings and subjective wellbeing using data from the China Household Finance Survey. They showed that the association between household savings and subjective wellbeing was in an inverted U-shape. Furthermore, they explored the heterogeneity of different groups and found that the optimal amounts of household savings varied among subsamples in terms of region, income, age, and risk attitude. Tharp and Parks-Stamm examined gender differences in the predictors of financial satisfaction using data from the Panel Study of Family Dynamics in Taiwan. They showed that gender differences are observed in all three samples, all adults, working adults and married working adults. In particular, income is more strongly associated financial satisfaction among men than women, education is more strongly associated with financial satisfaction among women than men, and negative affect as more strongly associated with financial satisfaction among women than men. Su, Huang, and Lin investigated the roles of house price expectations and mortgages in urban dwellers' subjective wellbeing in China. They found that house price expectations have a negative influence on the subjective wellbeing only for homeowners without a home loan. For homeowners with a home loan, mortgages have a negative impact on the subjective wellbeing. Warmath, Grable, Chen, and Kwak examined cultural differences in the role of willingness to take financial risk in an individual's objective financial outcomes and subjective financial wellbeing. Using data collected in South Korea, Taiwan, and the United States, they found support for a cushion in the association between material hardship and present and future financial wellbeing.

Two papers examined factors affecting consumption behavior. Kondratjeva, using panel data from nationally representative household surveys in Nepal, investigated how borrowing from different channels and for different purposes is associated with household investment and consumption expenditure. She showed that formal and informal loans are used to finance different spending needs, and intended credit purposes tended to reflect actual spending of borrowed funds. Using data from the China Household Finance Survey, Li, Song, $\mathbf{W u}$, and Huang examined the association between access to online consumer credit and household consumption. They found that online consumer credit has a significantly positive relationship with household consumption. Heterogeneity analysis showed that the relationship between online consumer credit and household consumption is more obvious among poorer households and households resided in less developed areas, which partially reflects the inclusiveness of online consumer credit.

Acknowledgments. We thank the Editor-in-Chief, Ron Hill, for his encouragement and guidance for developing and implementing the special issue. Jennifer Breitenbach, the editorial assistant, provided able and prompt assistance whenever we need her help. Several other Associate Editors helped the peer review process who are Jeff Langenderfer, Elizabeth Minton, and Lucie Ozanne. Finally, we thank reviewers who helped review papers for this special issue and provided thoughtful recommendations for the editors and constructive comments for the authors. They are listed below:

$\begin{array}{lll}\text { Aaron Arndt } & \text { Andrew Hanks } & \text { Brahim Chekima } \\ \text { Adam Ka-Lok Cheung } & \text { Andrew Yee } & \text { Brenda Cude } \\ \text { Akon Ekpo } & \text { Anne Hamby } & \text { Charles Makanyeza } \\ \text { Alessandro Bucciol } & \text { Benjamin Voyer } & \text { Christopher Prentice } \\ \text { Alexi Gloukhovtsev } & \text { Biao Luo } & \text { Chuanyi Tang }\end{array}$




Chung-Tung Lin
Clore Ki
Courtney Azzari
Dee Warmath
Derek Tharp
Douglas J. Crookes
Elison Lim
Elizabeth Miller
Eva Zhao
Felix Septianto
Frank Maretela
Fuzhong Chen
Genevieve O'Connor
Geoffrey Paulin
Gregory Colson
HanNa Lim
Hao Zhang
Herbert Jack Rotfeld
Hongjoo Woo
Honglei Lie
Ilana Shanks
In Han Song
Jack Hou
Jaihak Jung
Je Young Lee
Jessie Fan
Jin Huang

\begin{tabular}{ll} 
Jin Su & Po-Wen She \\
Jinhe Han & Pui Sun Tam \\
Jiří Zeman & R. G. Vishnu Menon \\
Jiyoung Hwang & Rimple Manchanda \\
Jolie Shi & Robert Nielsen \\
Jooran Kim & Rui Yao \\
Joyce Serido & Sarah Benmoyal-Bouzaglo \\
Jr-Tsung Huang & Sherman Hanna \\
Junhong Yang & So-Hyun Joo \\
Justine Farrell & Srinivas Benugopal \\
Kathleen Seiders & Srinvias Sridharan \\
Kelmara Vieira & Sumit Sakar \\
Kyoung Tae Kim & Swarn Chatterjee \\
Lan Chaplin & Tao Guo \\
Li Cui & Ting Chi \\
Li Ma & V. Dao Truong \\
Liqiong Lin & Varsha Jain \\
Lisa Bolton & Xiangyi Meng \\
Lorna Christie & Xiaomeng Lu \\
Lu Fan & Xuequn Wang \\
Marie Yeh & Yang Li \\
Melissa Wilmarth & Yang Sun \\
Min Jae Lee & Yanyan Chen \\
Mingming Shi & Yoon Lee \\
Nilton Porto & Yu Wu \\
Ou Wang & \\
Piotr Bialowolski & \\
\hline
\end{tabular}

Jin Su

Jinhe Han

Jiyoung Hwang

Jolie Shi

Jooran Kim

Joyce Serido

Jr-Tsung Huang

Junhong Yang

Justine Farre

(

Kelmara Vieira

Kyoung Tae Kim

Li Ma

Liqiong Lin

Lisa Bolton

Lorna Christie

Lu Fan

Marie Yeh

Melissa Wilmarth

Min Jae Lee

Pialowolski
Po-Wen She

R. G. Vishnu Menon

imple Manchanda

Robert Nielsen

Rui Yao

Sherman Hanna

So-Hyun Joo

Srinivas Benugopa

ias Sridharan

Sumit Sakar

Swarn Chatterjee

Chi

V. Dao Truong

Xuequn Wang

Yang Sun

Yanyan Chen

Yoon Lee

Yu Wu 